in vivo $35: 2495-2501(2021)$

doi:10.21873/invivo.12530

\title{
Diabetes Mellitus as a Prognostic Factor for Locally Advanced Rectal Cancer
}

\author{
DRAGOS EUGEN GEORGESCU ${ }^{1,2^{*}}$, TRAIAN PATRASCU ${ }^{1,2}$, TEODOR FLORIN GEORGESCU $^{1,3}$, ADRIAN TULIN $^{1,4^{*}}$, \\ LIVIU MOSOIA $^{1,5}$, NICOLAE BACALBASA ${ }^{6,7^{*}}$, OVIDIU STIRU ${ }^{8,9}$ and MIHAI-TEODOR GEORGESCU ${ }^{10,11}$ \\ ${ }^{1}$ Department of General Surgery, "Carol Davila” University of Medicine and Pharmacy, Bucharest, Romania; \\ ${ }^{2}$ Department of General Surgery, "Dr. Ion Cantacuzino” Clinical Hospital, Bucharest, Romania; \\ ${ }^{3}$ Department of General Surgery, Bucharest Clinical Emergency Hospital, Bucharest, Romania; \\ ${ }^{4}$ Department of General Surgery, Clinical Emergency Hospital "Prof. Dr. Agrippa Ionescu”, Bucharest, Romania; \\ ${ }^{5}$ Department of General Surgery, Central Military Emergency Hospital “Dr. Carol Davila”, Bucharest, Romania; \\ ${ }^{6}$ Department of Obstetrics and Gynecology, \\ "Carol Davila" University of Medicine and Pharmacy, Bucharest, Romania; \\ ${ }^{7}$ Department of Visceral Surgery, Center of Excellence in Translational \\ Medicine "Fundeni" Clinical Institute, Bucharest, Romania; \\ ${ }^{8}$ Emergency Institute for Cardiovascular Diseases Prof. Dr. C.C. Iliescu, Bucharest, Romania; \\ ${ }^{9}$ Department of Cardio-Thoracic Pathology, \\ "Carol Davila” University of Medicine and Pharmacy, Bucharest, Romania; \\ ${ }^{10}$ Department of Radiotherapy II, "Prof. Dr. Alex. Trestioreanu” Institute of Oncology, Bucharest, Romania \\ ${ }^{11}$ Discipline of Oncology, Department 8 (Radiology, Oncology, Haematology), \\ "Carol Davila" University of Medicine and Pharmacy, Bucharest, Romania
}

\begin{abstract}
Background/Aim: Currently, the impact of diabetes mellitus (DM) on rectal cancer patients is complex and just partly elucidated. The purpose of this study was to investigate the impact of diabetes mellitus on rectal cancer patients focusing on tumor differentiation grade, neoadjuvant chemoradiotherapy (NACRT) response, disease-free (DFS) and overall (OS) survival. Patients and Methods: Our study's population consisted of a group of 53 patients diagnosed with locally advanced rectal cancer, who underwent NACRT, followed by radical oncological surgery. This patient population was further divided into two groups according to diabetes presence. Results: Downstaging rates, local control, $D F S$, and $O S$ were lower in the DM subgroup compared to the non-DM locally advanced rectal cancer patients. Conclusion: The presence of DM at the time of diagnosis of
\end{abstract}

This article is freely accessible online.

*These Authors contributed equally to the present study.

Correspondence to: Georgescu Teodor Florin, Bd. Pipera, nr.1 VIIIC, et. 2, ap. 36, Voluntari, Ilfov county, 077190, Romania. Tel: +40 745161261, e-mail: florin.georgescu1@yahoo.com

Key Words: Diabetes, rectal cancer, radiochemotherapy. locally advanced rectal cancer patients may be a negative predictive factor for response to neoadjuvant therapy, distant metastases, and local recurrences rates.

Diabetes mellitus (DM) is one of the main chronic metabolic diseases, which have been linked to kidney, heart, and nerve damage. Currently, 422 million people worldwide have diabetes, and, despite global preventive measures, incidence and prevalence rates have been constantly increasing in the last decades (1). One of the most investigated organ-related consequences of DM is the one on kidney function (2-4), a life-threatening association if we consider the role of DM in end-stage renal disease (5).

Previous retrospective studies have reported that, for other pelvic tumors (e.g. cervix uteri, bladder), amongst other irradiation response predictive factors, such as smoking status, treatment duration, radiation total dose, target volume proximity, and local anatomy, DM can also act as one of these clinically meaningful factors for the increased incidence of adverse events development (6-8). In the last decade, after an increase in colorectal cancer incidence worldwide, the connection between DM and this malignancy has been thoroughly investigated (9). There are several studies showing that patients with rectal cancer and DM have a poorer prognosis than non-DM patients (10). Although diabetic patients with rectal cancer have an inferior 
prognosis, few studies have examined the impact of diabetes on the response to neoadjuvant chemoradiotherapy (NACRT), a negative impact possibly being an explanation for the poorer prognosis. Although no mechanism has been described to explain this phenomenon, most literature data suggest that NACRT is less effective in patients with diabetes $(11,12)$. The vast majority of studies that have investigated the impact of diabetes on the prognosis of patients with colorectal tumors have either included patients with colorectal neoplasms (13-15) or only those with colon cancer $(16,17)$. The association of diabetes with rectal cancer has rarely been found in patients with rectal neoplasms apart from those with colon neoplasia (18).

The association between diabetes and the survival of patients with colorectal cancer is still debatable; while some international studies have demonstrated a significant impact of diabetes on survival rates $(13,19)$, other studies considered that other risk factors (e.g. smoking, behavioral) have the greatest impact, and not DM $(14,16)$. This study aimed to analyze patients with locally advanced rectal neoplasms, who underwent NACRT, followed by radical surgery.

\section{Patients and Methods}

After obtaining Ethical Committee approval, we recruited 53 patients in this study, who were homogeneous in terms of preoperative staging (stage II-III/Dukes B and C); all patients were staged according to the institutional protocol with colonoscopy, pelvic magnetic resonance imaging (MRI), and thorax-abdomen computed tomography (CT) scanning. Patient population characteristics are presented in Table I. Following complete clinical staging, the therapeutic decisions were discussed in the institutional multidisciplinary board and all patients were scheduled for NACRT followed by radical surgery. NACRT consisted of long-course 3D conformal external beam radiotherapy up to a total dose of $50 \mathrm{~Gy}$ using a conventional fractionation schedule, and oral capecitabine administered for radiosensitization at $1600 \mathrm{mg} / \mathrm{m}^{2} /$ day, (MondayFriday) for 5 weeks. One month following radiotherapy, clinical reevaluation was performed by colonoscopy, and MRI of the abdomen and pelvis. Two months following the end of NACRT, clear margin radical surgery was performed in all patients by the same surgical team according to tumor location. For 23 patients, considering the postoperative pathology examination results that revealed the lack of tumor regression after NACRT (poor or no response), adjuvant chemotherapy consisting of 6 cycles of oxaliplatin $130 \mathrm{mg} / \mathrm{m}^{2} \mathrm{IV}$ day 1 and capecitabine $1000 \mathrm{mg} / \mathrm{m}^{2}$ twice daily during the days 1-14, was added three-weekly ( $\mathrm{q} 3 \mathrm{w})$. After the treatment, patient follow-up was carried out during a period of 5 years.

The study was conducted according to the guidelines of the Declaration of Helsinki, and approved by the Institutional Review Board of Prof. Dr. Alex. Trestioreanu Institute of Oncology (16751/28.11.2018). Informed consent was obtained from all subjects involved in the study.

For statistical analysis we used Microsoft Excel (Microsoft Office, Redmond, WA, USA), GraphPad 6 Prism (GraphPad Software, San Diego, CA, USA) and MedCalc 14.1 (MedCalc
Table I. Patient population characteristics.

\begin{tabular}{lcc}
\hline & DM group & Non-DM group \\
\hline No. pts. & 20 & 33 \\
Age & 61 & 63.1 \\
Males/females & $23 / 9$ & $30 / 4$ \\
Comorbidities & & \\
$\quad$ Cardiovascular & 3 & 3 \\
$\quad$ Gastrointestinal & 1 & 1 \\
TNM stage & 11 & 18 \\
II & 9 & 15 \\
III & & \\
\hline
\end{tabular}

DM: Diabetes mellitus; pts: patients; TNM: tumor-node-metastasis.

Software Ltd, Ostend, Belgium). We used $t$-test for independent variables, Spearman's rank correlation coefficient and Kaplan-Meier curves for survival analysis.

Patients were divided according to the presence of DM in two relatively balanced subgroups in terms of patient numbers, stage, and treatment; one comprised 20 diabetic patients and the other 33 non-diabetic patients.

The two groups were similar regarding duration of tumor and comorbidities. In the diabetic group we encountered two patients with arterial hypertension, one patient with New York Heart Association (NYHA) two with heart failure and one patient with a laparoscopic cholecistectomy in surgical antecedents. The duration of type 2 diabetes mellitus ranged between 3 and 10 years. Four patients were treated with insulin, while the rest had oral hypoglycemic medication, with relatively good glycaemic control. In the non-diabetic group, we found two patients with NYHA cardiac heart failure, one patient with arterial hypertension, and one patient with ulcerohemoragic rectocolitis.

We investigated the possible association between DM and tumor differentiation grade, in order to objectify whether diabetic patients are more prone to more aggressive forms of rectal neoplasm. Comparing the two groups according to several parameters, the extent to which the presence of diabetes influences the response to neoadjuvant treatment and the long-term prognosis by the occurrence of local recurrence or distant metastases, as well as its effect on overall survival was shown.

\section{Results}

Regarding the distribution of patients according to age and gender (Figure 1), the number of male patients with rectal cancer was higher than that of female patients (40 vs. 13); the average age at diagnosis among women was $58.15 \pm 2.69$ vs. 64.00土1.47 among men $(p=0.05)$.

Our primary study objective was to evaluate whether DM correlates with tumor aggressiveness in rectal cancer patients. Therefore, we analyzed the distribution of patients according to tumor differentiation degree and no association was found between DM and this tumor characteristic $(p=0.79)$ (Figure 2A). Additionally, we also classified patients into well and moderate tumor differentiation groups 
A

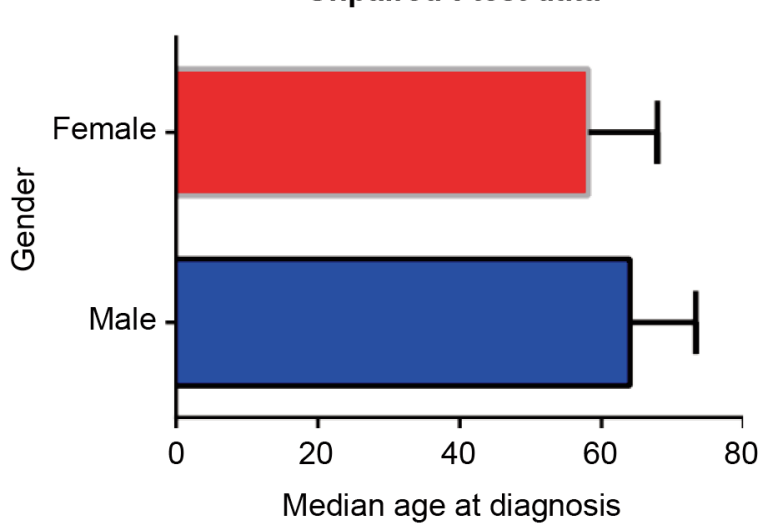

B

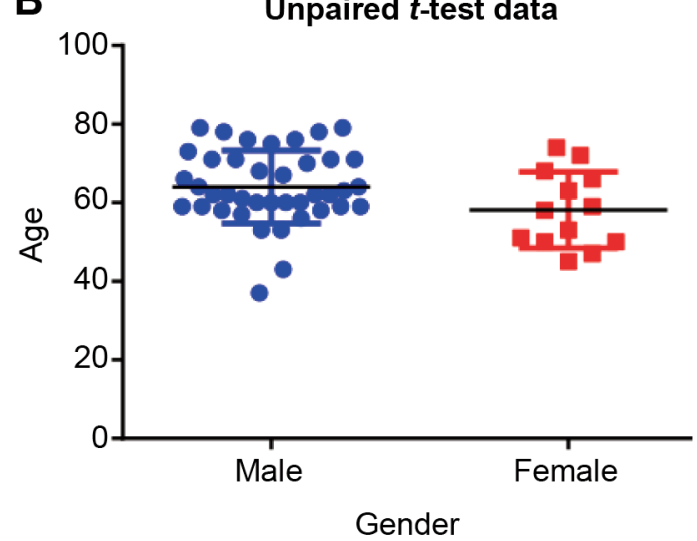

Figure 1. Patient distribution according to: (A) Age; (B) Gender, (unpaired t-test, $p=0.05$ ).

A

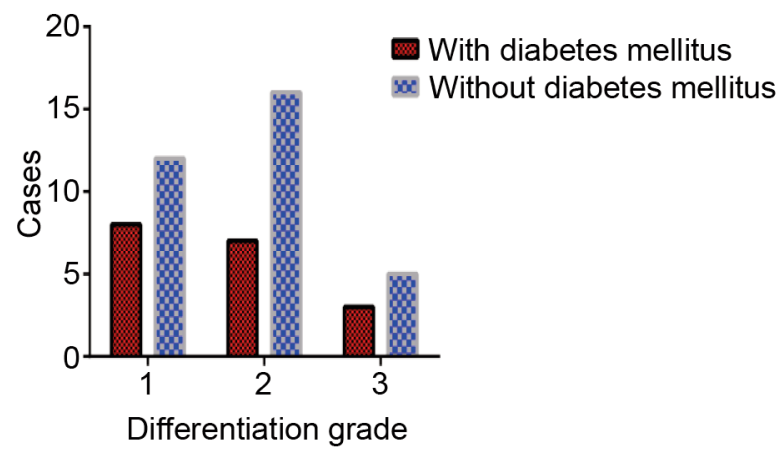

B

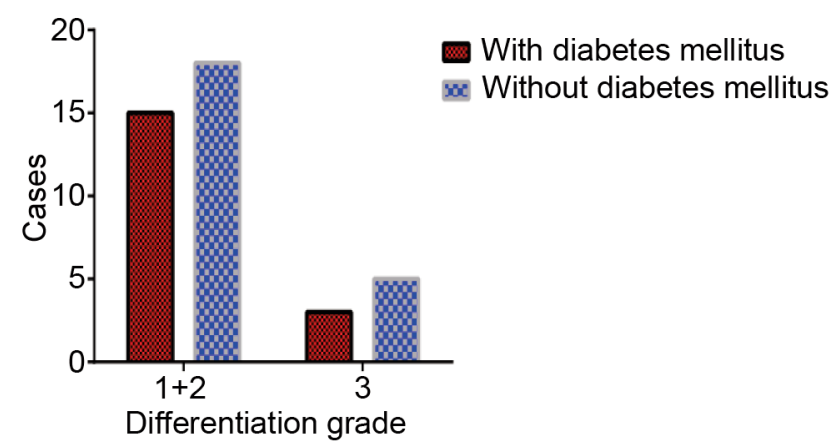

Figure 2. Relationship of diabetes mellitus with rectal cancer differentiation grade. (A) Individual differentiation grades; (B) Cumulated moderate and high differentiation grades (chi-square for trend).

to examine if DM can interfere with tumor grading (Figure 2B). Although the frequency of distribution between groups was not statistically significant, grouping the differentiation degrees with a cut-off value of 2 allowed us to evaluate the odds ratio $(\mathrm{OR}=1.38)$ and Relative Risk $(\mathrm{RR}=1.212)$. This further allowed us to report DM as a risk factor for the development of less differentiated tumors.

We also evaluated the impact of DM on the response to NACRT, considering that a positive correlation might suggest a poorer prognosis among patients with rectal cancer and DM. The statistical analysis of our patient population data revealed significantly higher rates of patients with downstaging after NACRT in the non-DM subgroup (Figure 3 ), (relative risk $=2.476$ and $p=0.0058$ ) which allowed us to conclude that the presence of diabetes at the time of diagnosis may be a predictive factor for a poor response to NACRT in rectal cancer patients.
The patients included in the study were monitored for a period of 5 years, assessing the correlation between the presence of DM and the occurrence of local or distant recurrences. From the results gathered $(\mathrm{RR}=2.3, \mathrm{OR}=3.7)$ and presented in Figure $4 \mathrm{~A}$ we can conclude that $\mathrm{DM}$ is a major risk factor for the development of local recurrences in patients with rectal cancer following NACRT $(p=0.03)$. Also, our results $(\mathrm{RR}=2.12$ and $\mathrm{OR}=3.03$ ), presented in Figure 4B, support the theory that diabetes is a risk factor for the development of metastasis in patients with rectal cancer, although a statistically significant distribution was not achieved $(p=0.12)$.

The average survival in the DM rectal cancer patient group was 17.5 months vs. 59 months for the non-DM subgroup. The impact of DM was best evidenced $(p=0.018)$ at 1 -year follow-up, when only $60 \%$ of patients in the DM patient subgroup survived, compared to $84.8 \%$ in the nonDM patient subgroup (Figure 5). 

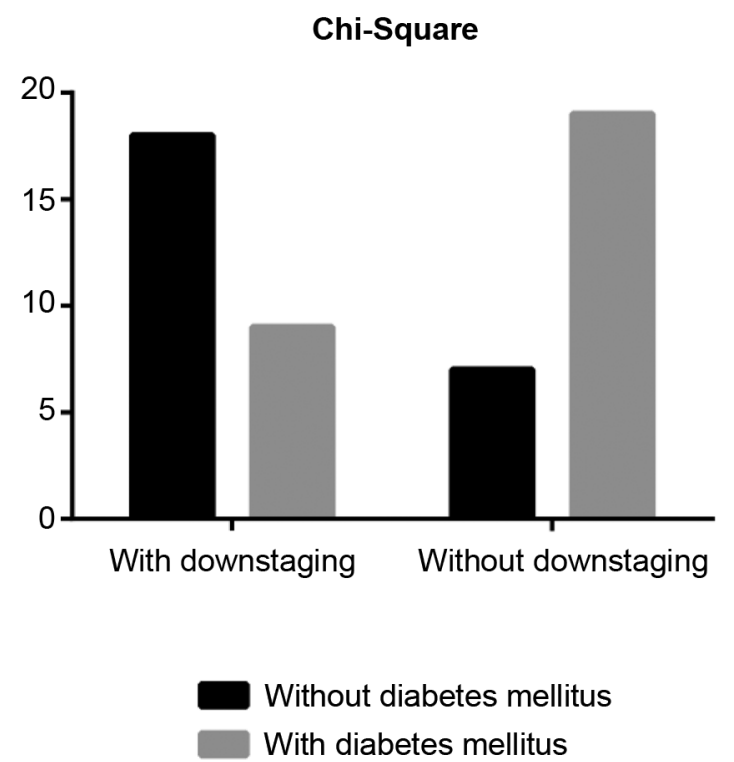

Figure 3. Downstaging rates following neoadjuvant chemoradiotherapy. There were higher rates of patients with downstaging after neoadjuvant chemoradiotherapy in the non-diabetes mellitus (DM) subgroup (33) than in the DM subgroup (20), (chi-square, $p=0.0058)$.

\section{Discussion}

Historically, colon and rectal cancers have been analyzed together, although a number of parameters may differ between the proximal and distal locations in the colon and especially between the colonic and rectal locations. Standard treatment for rectal adenocarcinoma involves NACRT to shrink the tumor prior to surgical resection, whereas for colonic adenocarcinoma the standard treatment involves surgical resection followed by adjuvant targeted therapies. Most studies that have investigated the association between diabetes and survival have either included patients with colorectal neoplasms (12-14) or only those with colon cancer $(16,17)$, and the reports of the association between diabetes and mortality in patients with rectal cancer analyzed separately from those with colonic neoplasms have been the exception (18).

Compared to the age at diagnosis, contrary to the results of our study, some studies have shown that women are usually about a decade older than men when they develop this disease (20), with males having a lower participation in screening programs $(21,22)$.

The association between DM and colorectal cancer appears to be complex and just partly elucidated. There are several potential mechanisms described, by which diabetes may interfere with the process of carcinogenesis. Most tumor cells express receptors for insulin and insulin-like growth factors (IGF-1), which may be stimulated in the presence of diabetes, due to hyperinsulinemia secondary to endogenous production or exogenous insulin administration (23-26). Activation of these receptors may be stimulated by different signaling pathways in response to cancer proliferation and progression (27). Another incriminated mechanism for carcinogenesis in diabetics is hyperglycemia because tumor cells require high levels of glucose in order to generate the necessary ATP for cell division (26, 28). Malignant progression in diabetics may also benefit from the associated chronic inflammatory process, especially in obese patients, through the released cytokines (29).

A review of 534 patients with colorectal cancer found worse histopathological features in patients with diabetes than in non-diabetics (30). These histopathological characteristics are associated with a worse prognosis for colorectal cancers. Patients with poorly differentiated and undifferentiated tumors have lower survival rates than those with welldifferentiated tumors. No differences have been reported in the literature between the tumor grading of diabetic patients compared to non-diabetics, but most studies were on colon or colorectal cancer and not specifically on rectal cancer (30, 31). In our study, patients with DM and rectal cancer were more prone to less differentiated cancer cell subtypes than their non-DM counterparts. Hyperinsulinemia, activation of IGF-1 receptors, and hyperglycemia present in diabetic patients may stimulate proliferation, angiogenesis, local invasion, and distant dissemination (30). One of the drawbacks of our study was the lack of more precise pathological data, like molecular biology tests and immunohistochemistry, since there are studies (32) reporting the impact of different tumor biomarkers on the treatment response of rectal cancer.

Although NACRT has been adopted as a therapeutic standard for locally advanced rectal cancer for a long time, so far, no molecular biomarker, studied as a potential predictive factor for tumor resistance to radiochemotherapy, has been implemented in current clinical practice (20).

Rectal cancer response to NACRT has been unanimously considered an important prognostic factor for this disease, that is why current research $(32,33)$ is focusing on predicting patients that would have an increased benefit from this therapeutic approach. Rectal cancer tissue is highly inflammatory, and the levels of inflammatory markers may correlate with obesity status (34). Although our study reported higher relapse rates for DM rectal cancer patients, we should also consider that DM oncological patients suffering that undergo surgery following NACRT usually have higher rates of surgical complications, especially wound infection, and need more treatment recovery time (35). Blood vessel damage is responsible for these surgical complications, and radiotherapy and DM have synergistic effects. That is why, for selected patients, especially for biopsy-proven pathologic complete responders following NACRT, a non-surgical 
A

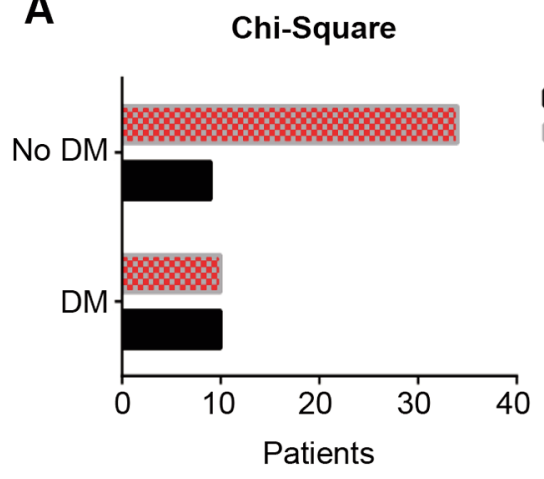

B

With relapse Without relapse

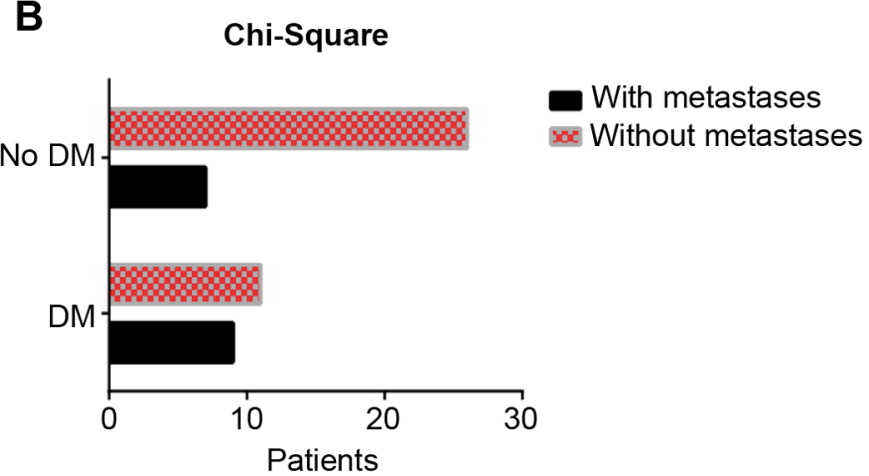

Figure 4. Diabetes mellitus impact on rectal cancer relapse. A) DM is a major risk factor for the development of local recurrences in patients with rectal cancer following NACRT ( $p=0.03)$. B) Diabetes is a risk factor for the development of metastasis in patients with rectal cancer.

watch-and-wait approach would be more suitable. Some studies $(36,37)$ suggest that even for the watch-and-wait patients, even after local relapse, surgery could still be delayed, and replaced with chemotherapy and reirradiation. Especially for some DM patients, special postoperative measures were taken for healing acceleration $(38,39)$.

A study conducted by Van de Poll-Franse et al. (40) found a statistically significant association between pre-existing diabetes and the risk of mortality in both colon and rectal cancer patients, which were independently analyzed. Another study that was carried out in Korea (18) describes patients with colorectal cancer and DM as having lower DFS rates than their non-DM counterparts. However, in this study DM had a negative impact on OS rates in patients with colon cancer, but not in those with rectal neoplasm.

Considering colon and rectal cancer independently, diabetes was associated with worse overall and disease-free survival, statistically significant in colonic pathology but not in the case of patients with rectal neoplasm. A possible explanation for the discrepancy regarding the Van de PollFranse et al. study (40) may be the racial difference of the patients investigated in the two studies.

One of the main limitations of our research is that it is a small-scale study, which might suggest that the findings cannot be generalized to the whole population. However, it is widely accepted that statistically significant findings in small sample studies should be managed as evidence for further exploration. Therefore, controlled validation studies across multiple sites to confirm reproducibility and reliability of these results are needed.

\section{Conclusion}

The aim of this study was to investigate the influence of DM on the early results after NACRT and the long-term

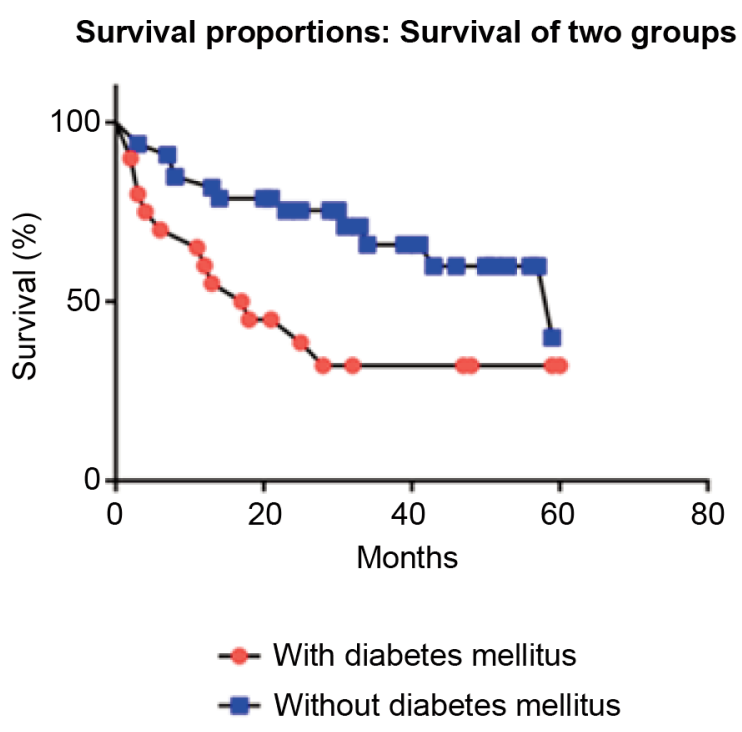

Figure 5. One-year overall survival rates in diabetes mellitus (DM) (12/20) vs. non-DM (28/33) rectal cancer patients, (log-rank/mantelcox test, $p=0.018$ ).

oncosurgical outcomes after surgery for rectal cancer using data prospectively obtained in a representative number of patients. Following our data analysis, we concluded that regarding tumor differentiation, DM was a risk factor for the development of low differentiated tumors. Also, regarding the response to NACRT, the presence of diabetes at the time of diagnosis may be a predictive factor for a poor response to NACRT in rectal cancer patients. Our study confirmed the negative impact of DM on survival rates in rectal cancer patients, with an almost $70 \%$ shortening of the average OS, compared to non-DM rectal cancer patients. Therefore, for 
DM rectal cancer patients, the therapeutic approach and also the follow-up should be tailored for both diseases. Therefore, future studies on the association between rectal cancer and DM should focus more on the DM-related factors, such as anti-diabetic medication and glycemic control, and the DMrelated comorbidities and their impact on rectal cancer characteristics such as aggressiveness and survival.

\section{Conflicts of Interest}

The Authors declare no conflicts of interest in relation to this study.

\section{Authors' Contributions}

Conceptualization, D.E.G and M.T.G; methodology, T.P.; software, F.T.G., A.T., L.M; validation, D.E.G., T.P. and M.T.G.; formal analysis, T.P, L.M.; investigation, D.E.G.; resources, D.E.G., M.T.G.; data curation, F.T.G., A.T.; writing-original draft preparation, D. E.G. N.B., O. S.; writing-review and editing, M.T.G, L.M.; visualization, F.T.G.; supervision, T.P., A. T.; project administration, D.E.G., M.T.G, statistical analysis, D.E.G. All Authors have read and agreed to the published version of the manuscript.

\section{References}

1 World Health Organisation: Diabetes. Available at: https://www.who.int/health-topics/diabetes\#tab=tab_1 [Last accessed on May 31, 2021]

2 Balcangiu stroescu A, Tanasescu M, Diaconescu A, Raducu L, Balan D, Mihai A, Tanase M, Stanescu I and Ionescu D: Diabetic nephropathy: a concise assessment of the causes, risk factors and implications in diabetic patients. Revista de Chimie 69(11): 3118-3121, 2020. DOI: 10.37358/RC.18.11.6695

3 Totan A, Balcangiu-stroescu A, Melescanu imre M, Miricescu D, Balan D, Stanescu I, Ionescu D, Timofte D, Tanasescu M and Greabu M: XOR - Possible correlations with oxidative stress and inflammation markers in the context of diabetic kidney disease. Revista de Chimie 70(4): 1396-1398, 2020. DOI: 10.37358/ RC.19.4.7135

4 Timofte D, Dragoș D, Măndiţă A, Balcangiu-stroescu A, Tănăsescu M, Bălan D, Răducu L, Avino A and Ionescu D: Risk factors for stroke in patients with chronic kidney disease. Internal Medicine 17(1): 35-44, 2021. DOI: 10.2478/inmed2020-0100

5 Nasri H and Rafieian-Kopaei M: Diabetes mellitus and renal failure: Prevention and management. J Res Med Sci 20(11): 1112-1120, 2015. PMID: 26941817. DOI: 10.4103/17351995.172845

6 Romano KD, Hill C, Trifiletti DM, Peach MS, Horton BJ, Shah N, Campbell D, Libby B and Showalter TN: High dose-rate tandem and ovoid brachytherapy in cervical cancer: dosimetric predictors of adverse events. Radiat Oncol 13(1): 129, 2018. PMID: 30012164. DOI: 10.1186/s13014-018-1074-2

7 Georgescu MT, Georgescu DE, Georgescu TF and Serbanescu LG: Changing the prognosis of metastatic cervix uteri adenosquamous carcinoma through a multimodal approach: a case report. Case Rep Oncol 13(3): 1545-1551, 2020. PMID: 33564296. DOI: $10.1159 / 000511564$
8 Georgescu MT, Moldoveanu VG, Ileanu BV and Anghel R: Dosimetric influence of uterus position in cervix cancer high-doserate brachytherapy. Romanian J Phys 61(9-10): 1557-1566, 2016.

9 Agache A, Mustăţea P, Mihalache O, Bobîrca FT, Georgescu DE, Jauca CM, Bîrligea A, Doran H and Pătraşcu T: Diabetes mellitus as a risk-factor for colorectal cancer literature review current situation and future perspectives. Chirurgia (Bucur) 113(5): 603-610, 2018. PMID: 30383987. DOI: 10.21614/ chirurgia.113.5.603

10 van de Poll-Franse LV, Haak HR, Coebergh JW, Janssen-Heijnen ML and Lemmens VE: Disease-specific mortality among stage I-III colorectal cancer patients with diabetes: a large populationbased analysis. Diabetologia 55(8): 2163-2172, 2012. PMID: 22526616. DOI: $10.1007 / \mathrm{s} 00125-012-2555-8$

11 Caudle AS, Kim HJ, Tepper JE, O’Neil BH, Lange LA, Goldberg RM, Bernard SA, Calvo BF and Meyers MO: Diabetes mellitus affects response to neoadjuvant chemoradiotherapy in the management of rectal cancer. Ann Surg Oncol 15(7): 1931-1936, 2008. PMID: 18418656 . DOI: $10.1245 / \mathrm{s} 10434-008-9873-6$

12 Skinner HD, Crane CH, Garrett CR, Eng C, Chang GJ, Skibber JM, Rodriguez-Bigas MA, Kelly P, Sandulache VC, Delclos ME, Krishnan S and Das P: Metformin use and improved response to therapy in rectal cancer. Cancer Med 2(1): 99-107, 2013. PMID: 24133632. DOI: $10.1002 /$ cam 4.54

13 Dehal AN, Newton CC, Jacobs EJ, Patel AV, Gapstur SM and Campbell PT: Impact of diabetes mellitus and insulin use on survival after colorectal cancer diagnosis: the Cancer Prevention Study-II Nutrition Cohort. J Clin Oncol 30(1): 53-59, 2012. PMID: 22124092. DOI: 10.1200/JCO.2011.38.0303

14 Morrison DS, Batty GD, Kivimaki M, Davey Smith G, Marmot M and Shipley M: Risk factors for colonic and rectal cancer mortality: evidence from 40 years' follow-up in the Whitehall I study. J Epidemiol Community Health 65(11): 1053-1058, 2011. PMID: 21389009. DOI: $10.1136 /$ jech.2010.127555

15 Noh GY, Hwang DY, Choi YH and Lee YY: Effect of diabetes mellitus on outcomes of colorectal cancer. J Korean Soc Coloproctol 26(6): 424-428, 2010. PMID: 21221244. DOI: $10.3393 / \mathrm{jksc} .2010 .26 .6 .424$

16 Shonka NA, Anderson JR, Panwalkar AW, Reed EC, Steen PD and Ganti AK: Effect of diabetes mellitus on the epidemiology and outcomes of colon cancer. Med Oncol 23(4): 515-519, 2006. PMID: 17303910. DOI: 10.1385/MO:23:4:515

17 Huang YC, Lin JK, Chen WS, Lin TC, Yang SH, Jiang JK, Chang SC, Lan YT, Wang HS, Liu CY, Yang YW and Teng HW: Diabetes mellitus negatively impacts survival of patients with colon cancer, particularly in stage II disease. J Cancer Res Clin Oncol 137(2): 211-220, 2011. PMID: 20387072. DOI: 10.1007/s00432-010-0879-7

18 Jeon JY, Jeong DH, Park MG, Lee JW, Chu SH, Park JH, Lee MK, Sato K, Ligibel JA, Meyerhardt JA and Kim NK: Impact of diabetes on oncologic outcome of colorectal cancer patients: colon $v s$. rectal cancer. PLoS One 8(2): e55196, 2013. PMID: 23405123. DOI: 10.1371/journal.pone.0055196

19 Meyerhardt JA, Catalano PJ, Haller DG, Mayer RJ, Macdonald JS, Benson AB 3rd and Fuchs CS: Impact of diabetes mellitus on outcomes in patients with colon cancer. J Clin Oncol 21(3): 433440, 2003. PMID: 12560431. DOI: 10.1200/JCO.2003.07.125

20 Chacko L, Macaron C and Burke CA: Colorectal cancer screening and prevention in women. Dig Dis Sci 60(3): 698-710, 2015. PMID: 25596719. DOI: 10.1007/s10620-014-3452-4 
21 Saab MM, Reidy M, Hegarty J, O’Mahony M, Murphy M, Von Wagner $\mathrm{C}$ and Drummond FJ: Men's information-seeking behavior regarding cancer risk and screening: A meta-narrative systematic review. Psychooncology 27(2): 410-419, 2018. PMID: 28728212. DOI: 10.1002/pon.4506

22 Teo CH, Ng CJ, Booth A and White A: Barriers and facilitators to health screening in men: A systematic review. Soc Sci Med 165: 168-176, 2016. PMID: 27511617. DOI: 10.1016/ j.socscimed.2016.07.023

23 Georgescu FT, Turculet CS, Georgescu DE and Beuran M: Correlations between clinico-pathological and prognostic parameters in patients with rectal cancer. Ro Med J 67(2): 158162, 2020. DOI: 10.37897/RMJ.2020.2.10

24 Denley A, Carroll JM, Brierley GV, Cosgrove L, Wallace J, Forbes B and Roberts CT Jr: Differential activation of insulin receptor substrates 1 and 2 by insulin-like growth factoractivated insulin receptors. Mol Cell Biol 27(10): 3569-3577, 2007. PMID: 17325037. DOI: 10.1128/MCB.01447-06

25 Ulanet DB, Ludwig DL, Kahn CR and Hanahan D: Insulin receptor functionally enhances multistage tumor progression and conveys intrinsic resistance to IGF-1R targeted therapy. Proc Natl Acad Sci USA 107(24): 10791-10798, 2010. PMID: 20457905. DOI: 10.1073/pnas.0914076107

26 Masur K, Vetter C, Hinz A, Tomas N, Henrich H, Niggemann B and Zänker KS: Diabetogenic glucose and insulin concentrations modulate transcriptome and protein levels involved in tumour cell migration, adhesion and proliferation. Br J Cancer 104(2): 345-352, 2011. PMID: 21179032. DOI: 10.1038/sj.bjc.6606050

27 Mardilovich K, Pankratz SL and Shaw LM: Expression and function of the insulin receptor substrate proteins in cancer. Cell Commun Signal 7: 14, 2009. PMID: 19534786. DOI: 10.1186/ 1478-811X-7-14

28 Vander Heiden MG, Cantley LC and Thompson CB: Understanding the Warburg effect: the metabolic requirements of cell proliferation. Science 324(5930): 1029-1033, 2009. PMID: 19460998. DOI: 10.1126/science.1160809

29 Giovannucci E, Harlan DM, Archer MC, Bergenstal RM, Gapstur SM, Habel LA, Pollak M, Regensteiner JG and Yee D: Diabetes and cancer: a consensus report. Diabetes Care 33(7): 1674-1685, 2010. PMID: 20587728. DOI: $10.2337 / \mathrm{dc} 10-0666$

30 Sharma A, Ng H, Kumar A, Teli K, Randhawa J, Record J and Maroules M: Colorectal cancer: Histopathologic differences in tumor characteristics between patients with and without diabetes. Clin Colorectal Cancer 13(1): 54-61, 2014. PMID: 24342823 DOI: $10.1016 /$ j.clcc.2013.10.002

$31 \mathrm{Li}$ J, Liu J, Gao C, Liu F and Zhao H: Increased mortality for colorectal cancer patients with preexisting diabetes mellitus: an updated meta-analysis. Oncotarget 8(37): 62478-62488, 2017. PMID: 28977962. DOI: 10.18632/oncotarget.19923

32 Georgescu TF, Turculet CS, Enache V, Georgescu DE, Georgescu MT and Beuran M: The importance of immunohistochemistry analysis of $\mathrm{p} 53$ and $\mathrm{Bcl}-2$ in patients with preoperative oncological therapy for rectal cancer. Romanian J Med Pract 15(2): 201-205, 2020. DOI: 10.37897/RJMP.2020.2.14
33 Georgescu MT, Patrascu T, Serbanescu LG, Anghel RM, Gales LN, Georgescu FT, Mitrica RI and Georgescu DE: When should we expect curative results of neoadjuvant treatment in locally advanced rectal cancer patients? Chirurgia (Bucur) 116(1): 1623, 2021. PMID: 33638322. DOI: 10.21614/chirurgia.116.1.16

34 Heeran AB, Dunne MR, Morrissey ME, Buckley CE, Clarke N, Cannon A, Donlon NE, Nugent TS, Durand M, Dunne C, Larkin JO, Mehigan B, McCormick P, Lynam-Lennon N and O'Sullivan $\mathrm{J}$ : The protein secretome is altered in rectal cancer tissue compared to normal rectal tissue, and alterations in the secretome induce enhanced innate immune responses. Cancers (Basel) 13(3): 571, 2021. PMID: 33540635. DOI: 10.3390/cancers13030571

35 Yao C, Nash GF and Hickish T: Management of colorectal cancer and diabetes. J R Soc Med 107(3): 103-109, 2014. PMID: 24334910. DOI: $10.1177 / 0141076813512121$

36 Georgescu DE, Georgescu MT, Bobircă FT, Georgescu TF, Doran H and Pătraşcu T: Synchronous locally advanced rectal cancer with clinical complete remission and important downstaging after neoadjuvant radiochemotherapy - Personalised therapeutic approach. Chirurgia (Bucur) 112(6): 726-733, 2017. PMID: 29288615. DOI: 10.21614/chirurgia.112.6.726

37 Tao R, Tsai CJ, Jensen G, Eng C, Kopetz S, Overman MJ, Skibber JM, Rodriguez-Bigas M, Chang GJ, You YN, Bednarski BK, Minsky BD, Delclos ME, Koay E, Krishnan S, Crane CH and Das P: Hyperfractionated accelerated reirradiation for rectal cancer: An analysis of outcomes and toxicity. Radiother Oncol 122(1): 146-151, 2017. PMID: 28057329. DOI: 10.1016/ j.radonc.2016.12.015

38 Răducu L, Avino A, Purnichescu Purtan R, Balcangiu-Stroescu AE, Bălan DG, Timofte D, Ionescu D and Jecan CR: Quality of life in patients with surgically removed skin tumors. Medicina (Kaunas) 56(2): 66, 2020. PMID: 32050413. DOI: 10.3390/ medicina56020066

39 Avino A, Jecan C, Cozma C, Stroescu A, Balan D, Ionescu D, Mihai A, Tanase M and Raducu L: Negative pressure wound therapy using polyurethane foam in a patient with necrotizing fasciitis. Materiale Plastice 55(4): 603-605, 2020. DOI: 10.37358/mp.18.4.5083

40 van de Poll-Franse LV, Houterman S, Janssen-Heijnen ML, Dercksen MW, Coebergh JW and Haak HR: Less aggressive treatment and worse overall survival in cancer patients with diabetes: a large population based analysis. Int J Cancer 120(9): 1986-1992, 2007. PMID: 17230509. DOI: 10.1002/ijc.22532
Received April 20, 2021

Revised May 29, 2021

Accepted May 31, 2021 